\title{
O SISTEMA ADMINISTRATIVO MICÊNICO A PARTIR DOS DOCUMENTOS EM LINEAR B
}

\author{
Juliana Caldeira Monzani ${ }^{1}$
}

\begin{abstract}
Resumo
O presente artigo visa apresentar o sistema administrativo micênico inferido a partir dos documentos em Linear B, em especial os tabletes. A essa discussão acrescenta-se o estudo específico de um tipo de documento: os vasos com alça em estribo. Tais recipientes foram concebidos para armazenamento e transporte de líquidos e variam muito em tamanho e acabamento, indo desde exemplares pequenos e refinados até vasos maiores e rústicos produzidos especificamente para o transporte. Nesta última categoria encontra-se um grupo de vasos que receberam inscrições, tendo sido produzidos, na sua maioria, no oeste de Creta, mas encontrados em grande número no continente, e por isso são peças importantes para elucidar as relações estabelecidas entre os centros administrativos micênicos na Península Balcânica e áreas produtivas em Creta.
\end{abstract}

\section{Palavras-chave}

Linear B; administração micênica; vasos com alça em estribo.

\footnotetext{
${ }^{1}$ Professora Doutora - Universidade Cidade de São Paulo, São Paulo, Brasil. Email: jmonzani@yahoo.com
}

Heródoto, Unifesp, Guarulhos, v.5, n.1 - 2020.1. p. $43-59$

DOI: $10.34024 /$ herodoto.2020.v5.11780 


\begin{abstract}
This article aims to present the Mycenaean administrative system from documents in Linear B, especially tablets. The specific study of a type of document is added to this discussion: vessels with stirrup handle. Such containers were conceived to store and transport liquids and vary greatly in size and finish, ranging from small, refined examples to larger and rustic vases produced specifically for transportation. In this last category is a group of vases that received inscriptions, mostly produced in western Crete, but found in great number in the continent, thus being important pieces to elucidate the relations established between the Mycenaean administrative centers in the Balkan Peninsula and productive areas in Crete.
\end{abstract}

\title{
Keywords
}

Linear B; Mycenaean administration; vases with stirrup handle. 


\section{Introdução}

A decifração dos documentos em Linear B realizada por Michael Ventris em 1952 comprovou que a língua registrada era uma forma arcaica do grego e a história dos gregos recuou até a Idade do Bronze. A estrutura social, política e econômica desse período, no entanto, é fundamentalmente diferente do mundo das poleis que emergiu a partir do século VIII a.C., fruto de um desenvolvimento próprio originado da reorganização realizada após a desestruturação da organização micênica. Os documentos em Linear B, juntamente com os vestígios arqueológicos, que são abundantes e variados, são as fontes primárias para o estudo do período micênico. Os documentos escritos mais antigos são datados de 1450 a.C., mas as evidências arqueológicas apontam para uma estruturação social bem estabelecida já em 1600 a.C. e um possível estabelecimento de novas populações na Península Balcânica a partir de 1900 a.C.

O contexto arqueológico indica que a escrita não era muito difundida no mundo micênico. Nenhum tablete foi encontrado em sítios menores, estando sempre associados aos centros administrativos. Desta maneira, Chadwick se sente seguro para afirmar que a escrita teria sido apenas uma ferramenta administrativa (1987, p. 11). Tal ideia é corroborada pelo seu total desaparecimento após o colapso dos centros administrativos micênicos.

\section{O sistema de escrita micênico}

O Linear B é um sistema de escrita utilizado pelos micênios no final da Idade do Bronze fundamentalmente para o registro e controle de atividades econômicas. O emprego do Linear B se dá de forma telegráfica e padronizada tendo como propósito transmitir informações precisas, de forma objetiva e sistemática. O padrão básico, a partir do qual pode haver uma variação muito restrita, é o emprego de uma ou mais palavras em silabário linear, geralmente um antropônimo ou um topônimo, seguido da inserção de um ideograma que especifica uma mercadoria ou matériaprima e, por fim, a determinação da quantidade a partir do uso de numerais ou, em casos específicos, sinais para pesos e medidas.

São três os tipos de suporte que chegaram até nós: os tabletes em argila, os vasos com inscrições geralmente pintadas e os nódulos de argila. Dentre os 5.500 documentos em Linear B a maioria são tabletes. O que não é claro 
é se existia um nível superior de documentos (papiros e/ou pergaminhos), embora muitos pesquisadores assumam que sim (Palaima, 2003 e Driessen, 1997 contra Bennet, 2001).

Os tabletes de argila apresentam duas formas básicas: página, sendo a altura maior o comprimento; e folha de palmeira, em que as proporções se invertem e o comprimento é maior que a altura. Esta última comporta de uma a três linhas de escritura, enquanto que a primeira pode ter até 25 linhas. Cnossos em Creta possui o maior acervo de tabletes, mas seu estado é mais fragmentário. São cerca de 4.300 peças das quais $75 \%$ são incompletas e $56 \%$ possuem menos de cinco sinais ou símbolos. O sítio de Pilos na Messênia aparece em segundo lugar em número de tabletes, possuindo cerca de 1300, mas o estado geral de conservação é melhor $50 \%$ estão completos - e o contexto de achado também é bem estabelecido, uma vez que grande parte pertence à sala dos arquivos, ou seja, os tabletes foram encontrados em seu contexto de armazenagem, enquanto que os de Cnossos estavam dispersos em várias áreas do edifício principal e em algumas áreas de descarte, ou seja, em contexto secundário. Os tabletes eram inscritos em argila crua e úmida, secos ao sol e armazenados, o que indica que eram arquivos temporários cuja vida útil seria, no máximo, de um ano. Uma vez que os tabletes secos ao sol são frágeis, é improvável que eles tenham sido produzidos em locais diferentes de seu contexto de achado. Isso pode sugerir também a existência de arquivos permanentes em materiais perecíveis que não chegaram até os dias atuais. Tal dado nos remete à característica fundamental da documentação: eles foram preservados porque foram cozidos em incêndios que destruíram os edifícios em que estavam armazenados. Representam, portanto, informações circunscritas ao período de distúrbios do mundo micênico (exceção feita aos fragmentos descartados em Cnossos que podem pertencer a períodos anteriores). Sendo assim, é preciso ter em mente que os tabletes têm datas diferentes, sendo que os de mais antigos seriam um grupo de Cnossos associados à destruição do edifício em torno de 1450/1430 a.C. e os mais recentes os de Pilos datados de 1200 a.C.

Os nódulos são pequenos pedaços de argila que possuem três faces, duas eventualmente escritas e uma com impressão de selo. Nos nódulos, diferentemente dos tabletes, os logogramas aparecem isolados, sem indicação numérica ou de medidas, uma vez que se assume que representem uma quantidade pré-estabelecida da mercadoria em questão. Os nódulos possuem regras padronizadas para o seu uso e a sua função principal era transmitir certa quantidade de informações básicas a respeito

Heródoto, Unifesp, Guarulhos, v.5, n.1 - 2020.1. p. 43-59

DOI: $10.34024 /$ herodoto.2020.v5.11780 
do item que eles acompanhavam. Os nódulos podem conter um antropônimo, um topônimo, um ideograma representando um tipo de mercadoria, às vezes um adjetivo para descrever o estado da mercadoria, e um termo econômico representando o tipo de transação ou obrigação cumprida. Em alguns casos apenas a impressão de um selo, sem qualquer inscrição, era o suficiente para transmitir a informação necessária (van Alfen, 1997, p. 267).

O último tipo de material que recebeu inscrições são os vasos. São, em sua maioria, vasos com alça em estribo para transporte com inscrições pintadas no ombro ou bojo antes da queima. Até o presente momento são conhecidos 197 vasos com inscrição em Linear B, dentre os quais 186 são vasos de transporte com alça em estribo. Diferentemente dos tabletes que eram provavelmente arquivos temporários e pertencentes a períodos distintos, os vasos, ao contrário, foram cozidos no momento de sua fabricação e possuem um contexto cronológico bem estabelecido e restrito a 1300 a.C. No entanto, nem o local de achado nem a data atribuída obtida no nível arqueológico da descoberta podem ser considerados a priori como contexto primário. Os vasos com alça em estribo são os documentos em Linear B que mais viajaram, a maioria tendo sido produzida em Creta e encontrada no continente grego, especialmente na Argólida e na Beócia: 74 foram encontrados em Tebas e 46 em Tirinto, e sendo os dois maiores conjuntos. As análises da composição química da pasta cerâmica demonstraram que eles foram produzidos no oeste de Creta, na região de Cidônia, de onde provém o terceiro maior grupo contando com 44 exemplares. Mesmo antes de tais análises os especialistas já haviam apontado que grande parte dos topônimos se referiam à porção ocidental da ilha.

Há ainda os selos que provavelmente serviam como etiquetas em caixas com tabletes ou lacres em portas de depósito. Neste último caso funcionavam para o controle da retirada de bens em quantidades padronizadas. A cada retirada de uma quantidade pré-estabelecida o selo seria retirado e guardado e, após o final de um determinado período, os selos eram contados, contabilizando o total de mercadorias retiradas e, por fim, descartados. 
As principais coleções de documentos pertencem aos sítios de Pilos e Cnossos. Nos demais sítios a documentação é muito fragmentária, embora seja igualmente relevante para a construção um quadro geográfico e econômico a respeito do mundo micênico. É importante pontuar as diferenças do corpus dos dois centros. Em Pilos foram encontrados arquivos centrais e o edifício possui uma única destruição estabelecida em 1200 a.C. Pode-se, portanto, falar em unidade dos arquivos e é provavelmente por esse motivo que não há os registros individuais em tabletes alongados em forma de folha de palmeira, considerados registros preliminares, mas sim recenseamentos de informação em tabletes maiores em formato de página. Em Cnossos, por outro lado, não temos este tipo de evidência que é característica de arquivos centrais que não foram encontrados nesse centro. Há pelo menos duas grandes destruições do edifício, e os incêndios decorrentes preservaram tabletes de épocas distintas, mas principalmente aqueles com informações parciais, quando os registros individuais foram registrados em tabletes em forma de folha de palmeira.

Com base nas inscrições dos tabletes as atividades econômicas relacionadas aos centros administrativos podem ser caracterizadas pela palavra micênica ta-ra-si-ja que significa quantidade pesada e preparada para processamento. O sistema tarasija fundamentava-se na coleta de matérias-primas pela autoridade central e na sua distribuição para trabalhadores dependentes ou parcialmente pendentes que eram pagos em espécie (Shelmerdine, 2008, p. 80). Os centros administrativos controlavam desta maneira a produção de algumas mercadorias específicas cujo destino era para uso do próprio centro, como é o caso dos armamentos e carros de guerra e que teriam um valor ligado ao status social, ou para exportação, como é o caso dos óleos perfumados dado o seu valor comercial (Killen, 2011, p. 163).

A título de nota, outro sistema que pode ser identificado nos tabletes é relacionado à palavra o-no, entendida pela maioria dos estudiosos como benefício, uma forma de pagamento dada a trabalhadores independentes pelo fornecimento de certos itens cuja produção não era controlada diretamente pelos centros, muito provavelmente pela falta de interesse comercial ou social dos mesmos. Seria o caso dos fabricantes de redes que aparecem nos tabletes ono, mas não nos tabletes que pertencem ao sistema tarasija. É interessante notar que os registros de transações associadas a benefícios constituem uma pequena parcela dos arquivos. Estes são em 
grande parte dedicados ao sistema tarasija, e isso se deve muito provavelmente porque o sistema ono não pertencia à principal esfera de atuação dos centros administrativos e o seu registro não apresentava a importância do controle que se fazia necessário no sistema tarasija.

Os tabletes propiciam uma gama de pesquisas a respeito da organização da produção agrícola e industrial, da extensão dos territórios controlados direta ou indiretamente e estudos a respeito das mãos dos escribas realizados, sobretudo, nos tabletes de Pilos e de Cnossos. Dentro do sistema tarasija, as séries Cn de Pilos e Da-Dg de Cnossos versam sobre rebanhos de ovelhas. Em Pilos o registro foi estruturado de duas maneiras: um topônimo seguido de um antropônimo e a informação sobre rebanho; ou um topônimo seguido de um antropônimo, mais um segundo antropônimo no genitivo, a palavra a-ko-ra e a informação sobre rebanho. Segundo Ventris e Chadwick na primeira edição de Documents in Mycenaean Greek de 1953, o segundo antropônimo estaria no genitivo porque ele seria um complemento determinativo do termo a-ko-ra - do grego agorá -, cujo sentido foi, grosso modo, entendido como assembleia, reunião, coleção, rebanho. Por isso tais indivíduos foram identificados com o termo coletor. Em Cnossos há um sistema semelhante, mas sem o uso explícito do vocabulário a-ko-ra. A fórmula encontrada em Cnossos é um antropônimo em maiúsculo seguido ou por um topônimo, ou por um topônimo e um segundo antropônimo às vezes no genitivo. O coletor está normalmente no genitivo, o que indicaria propriedade, e onde não há coletor assume-se que o proprietário seria o wanax ou o centro. Há quatro coletores identificados em Pilos, mas há pelo menos 15 coletores identificados nas séries Da-Dg em Cnossos. O total de ovelhas em Cnossos é muito maior, cerca de 19.000, contra 4.000 em Pilos. A semelhança mais importante entre Pilos e Cnossos é que um coletor pode ter rebanhos em vários lugares.

Há importantes debates a respeito da figura do coletor, mas em geral os autores parecem concordar que em Pilos os chamados coletores seriam funcionários administrativos do centro, responsáveis pela gerência de determinadas atividades, ainda que se discuta - tanto para Pilos quanto para Cnossos - se realizariam os registros sendo também escribas. $\mathrm{O}$ contexto mais claro em Pilos pode ser explicado pela unidade dos arquivos bem como o seu bom estado de conservação, à existência de um arquivo central, a uma menor extensão territorial e, consequentemente, a um número menor de coletores identificados, mas, sobretudo, pela história da 
ocupação e controle da região que se deu, provavelmente, através da expansão gradual a partir do centro administrativo.

A grande questão é quem seriam os coletores em Cnossos, problema dificultado pela falta de unidade dos arquivos, seu estado fragmentário e parcial, inexistência de um arquivo central, grande extensão territorial que o centro parece controlar - direta ou indiretamente - e o grande número de coletores.

John Bennet (1992) acredita que se tratam de proprietários locais e que a administração micênica teria sido construída aproveitando-se da préexistência de unidades econômicas regionais. Sua abordagem é bastante interessante pois considera a história prévia da administração em período minoico e da organização econômica de Creta, e por se aproximar da teoria de Mario Liverani sobre o modo de produção palaciano. Por outro lado, Pierre Carlier (1992) pensa que seriam funcionários, pois não identifica diferença no tratamento dos registros de rebanhos associados diretamente ao centro administrativo e aqueles associados aos coletores. Louis Godart (1992) atribui aos coletores uma proximidade muito maior com o poder, associando-os à família governante, e um controle direto de Cnossos sobre os territórios, uma vez que acredita que todas as propriedades e os rebanhos pertenciam ao centro. Jan Driessen (1992) é o único autor a considerar que existem duas fases dos arquivos, a primeira datada de 1450 a.C., e uma segunda da segunda destruição em 1370 a.C. Desta maneira aponta para a inexistência da figura do coletor na primeira fase, quando é possível identificar nos registros da Sala dos Tabletes de Carruagem apenas uma elite militar. Já na segunda fase distingue-se uma elite de nomenclatura, que também teria características militares, e uma elite econômica, que seriam os coletores. Por fim, John Killen (1995) afirma que os coletores seriam a elite governante uma vez que alguns nomes de coletores aparecem em outros registros como proprietários de mão de obra, produtos, terras, e também associados ao comércio externo.

\section{O lugar dos vasos com inscrição na administração micênica}

O vaso com alça em estribo é uma forma característica da Idade do Bronze, mas que não teve continuidade nos períodos posteriores. Tornou-se a marca registrada da cerâmica micênica de uso doméstico e de exportação durante 1400 a 1200 a.C. atingindo o seu auge de produção e circulação por volta de 1300 a.C., embora tenha sido provavelmente desenvolvido em 
Creta entre 1700 e 1600 a.C. Trata-se de uma forma especializada para o armazenamento, transporte e vertedura de líquidos. Nas publicações o vaso é comumente conhecido como stirrup jar, termo empregado por Arthur Evans, entre aspas, no relatório de escavação de 1902. O nome que se adota em português, "vaso com alça em estribo", nada mais é do que a tradução do termo em inglês mais utilizado pelos pesquisadores. De acordo com Halford Haskell (1985, p. 221) o vaso pode ser descrito como uma forma fechada com um pescoço falso central cilíndrico e estreito, permanentemente fechado por um disco de argila. Duas alças em forma de estribo saem do ombro até as bordas do disco. Colocado no ombro, próximo ao pescoço falso, está a verdadeira abertura. Seus elementos definidores estão, portanto, concentrados na parte superior do vaso: o pescoço falso fechado por um disco, a abertura verdadeira deslocada e as alças na forma de estribo.

Esses recipientes podem variar muito em tamanho e com relação ao tratamento da pasta cerâmica e por este motivo foram divididos em versões pequenas de cerâmica refinada tanto no tratamento da pasta quanto na decoração, e as versões maiores de cerâmica rústica (coarse ware). Arne Furumark (1941, p. 610) classificou os vasos com alça em estribo na forma 46 e depois os subdividiu em 22 tipos específicos (FS 164 a 185). Os vasos que receberam inscrição pertencem à forma FS 164. Essa é a forma dos grandes vasos com alça em estribo com cerâmica rústica e de exportação e armazenamento. Possuem uma fabricação altamente padronizada, apresentando uma altura média de 40 centímetros e capacidade que varia entre 12 e 14 litros. São encontrados em vários contextos, de habitações a armazéns, e em carregamentos de navios. Não são usualmente encontrados em sepulturas, sendo achados ocasionalmente nas de Creta e raramente em tumbas do continente grego. Os contextos de achado caracterizam tal forma como sendo utilitária, servindo principalmente para o transporte e armazenamento de grandes quantidades de líquidos, provavelmente óleo de oliva (embora vinho também seja uma possibilidade). O ápice de produção e circulação de tais vasos é de 1350 a 1300 a.C., um momento político e arqueológico complexo em Creta, mas que corresponde ao auge da expansão comercial micênica. Sua distribuição nos sítios costeiros do leste do Mediterrâneo é ampla, tendo sido exportados dos centros produtores no Egeu para Anatólia, Chipre, a costa da Palestina e o Egito. Sua presença também é atestada nos carregamentos dos navios naufragados em Uluburun, Quelidônia e Irina. Além de fazer parte do que parece ser uma rede intensiva de comércio com o Oriente Próximo, tais vasos também foram encontrados em menor 
número no sul da Itália, na Sicília e na Sardenha, atestando os contatos com o oeste do Mediterrâneo.

Dos 186 vasos com alça em estribo com inscrições, excetuando-se os fragmentos que trazem um sinal que não pode ser identificado e os vasos com um único sinal que pode ser a grafia da sílaba ka, mas cujo sentido é desconhecido, uma vez que não é uma abreviação conhecida nos tabletes, as inscrições dos vasos podem ser classificadas em duas categorias. Em 61 vasos as inscrições possuem apenas uma palavra, geralmente um antropônimo, com exceção de dois exemplares cuja inscrição é um topônimo. Em uma segunda categoria, que abrange 18 vasos, as inscrições possuem três palavras: um antropônimo no nominativo, seguido de um topônimo, e um antropônimo no genitivo. Nesta categoria a maioria (15) dos vasos pertencem ao conjunto encontrado no sítio de Tebas.

No segundo caso fica evidente o paralelo com a fórmula encontrada na série $\mathrm{D}$ dos tabletes de Cnossos a respeito de rebanho de ovelhas. Assumese que o primeiro antropônimo se refira ao produtor, o topônimo ao local de produção e o segundo antropônimo o destinatário, chamado de coletor. Existe um subgrupo no qual o destinatário é o wanax, pois em tais inscrições a terceira palavra não é um nome próprio, mas o adjetivo wa-naka-te-ro (relativo ao wa-na-ka) ou a sua abreviação, wa. Assim sendo, os vasos com inscrição parecem possuir a mesma distinção dos tabletes entre uma produção controlada diretamente pelos centros e outra controlada por um intermediário.

As inscrições dos vasos parecem reproduzir o sistema tarasija dos tabletes de ovelhas de maneira adaptada, apresentando, em sua maioria, apenas um antropônimo. A ausência dos demais elementos se explicaria pela redundância do uso dos mesmos. Assume-se que a mercadoria era conhecida, assim os vasos em si já indicariam de qual produto se tratava. Mesmo pode ser dito com relação à quantidade, seria desnecessário indicála uma vez que os vasos possuem sua capacidade volumétrica prédeterminada graças à padronização da sua manufatura. Desta maneira os vasos e suas inscrições pertenceriam a esfera administrativa do sistema tarasija.

Da mesma forma que os tabletes, os vasos e suas inscrições suscitam vários debates, dentre eles cabe mencionar a questão da literacia do pintor, uma vez que há exemplo de vasos muito próximos da tradição dos tabletes, como é o caso do único vaso de Elêusis, que usa uma linha para dividir o texto e os silabogramas são muito bem traçados, demonstrando que o autor 
era familiarizado com tais signos a ponto de saber como os traços eram feitos nos tabletes. No entanto, há também a exemplo de vasos ilegíveis como é o caso do recipiente encontrado no sítio de Orcômenos, em que há os signos que não são silabogramas reconhecíveis do Linear B. Estas duas inscrições encontram-se em polos opostos do espectro, sendo o primeiro a melhor versão de uma inscrição em vaso e o segundo a mais indecifrável, constituindo-se, no entanto, em exceções.

O principal debate se debruça sobre a função das inscrições dentro do sistema administrativo micênico. Apresenta-se a seguir uma síntese das principais abordagens.

Para Peter van Alfen (1997) os vasos com inscrição serviam como etiquetas de lotes e tinham como função monitorar o cumprimento da obrigação da produção, sendo que os destinatários das inscrições eram os receptores, embora o autor não especifique quem seriam. Tal hipótese explicaria o número pequeno de vasos com inscrição, bem como a sua inserção no sistema administrativo micênico. Joseph Maran (2005) é o primeiro pesquisador a considerar o contexto de achado no continente como contexto primário, ressaltando a concentração de tais vasos em Tebas e Tirinto, o que apontaria para um fluxo específico do oeste de Creta para a Beócia e a Argólida. O autor, no entanto, não considera que se trate de comércio entre a ilha e o continente, entendendo que Creta não tinha autonomia política, mas estaria submetida aos centros continentais em um sistema de vassalidade, dentro do qual os vasos representariam o pagamento de tributos. Julien Zurbach (2006), assim como van Alfen, enfatizou o papel das inscrições no contexto de controle interno da administração. Zurbach, no entanto, pensa em uma administração centrada em Creta, considerado pelo autor como o contexto primário de circulação e utilização dos vasos, enquanto que sua presença no continente se explicaria por serem bens de prestígio. Embora não fosse o objeto de estudo de Kevin Pluta em sua tese sobre a literacia na Idade do Bronze (2011) aponta que as inscrições no vaso atribuiriam certo prestígio ao seu conteúdo, e não ao recipiente, levando em consideração os contextos de achado no continente (em porões ou armazéns). Esta é a mesma abordagem de Yves Duhoux (2011), no entanto o autor se debruça em sua análise em uma amostragem pequena (só os vasos inteiros e com inscrições com leitura assegurada), embora tenha o mérito de reconhecer o continente como o contexto primário de utilização dos vasos, e associá-los aos tabletes que possuem a figura dos coletores. Considera que o pequeno número de vasos com inscrição aponta para um sistema de troca de presentes -

Heródoto, Unifesp, Guarulhos, v.5, n.1 - 2020.1. p. $43-59$

DOI: $10.34024 /$ herodoto.2020.v5.11780 
existente nas sociedades coetâneas do Oriente Próximo e também em Homero - e não de comércio. As inscrições, assim destituídas de qualquer função administrativa, teriam um valor simbólico na medida em que embelezam e atribuem prestígio ao vaso. Contra tal ideia Cinthia Shelmerdine (1985) já havia pontuado que tais vasos são rusticamente produzidos e decorados, elaborados não pela beleza, mas para o transporte de óleo em grandes quantidades, e que a aquisição de um valor de prestígio seria posterior. Anna Judson (2013) diferencia o que considera pseudo inscrições, - que teriam a função de atribuir prestígio ao vaso, uma vez que não poderiam ser lidas - das verdadeiras inscrições. Estas últimas estariam relacionadas à administração de Creta, aqui considerando, como muitos autores, o continente como contexto secundário. Para a autora, assim com os elementos estilísticos do vaso, as inscrições indicariam, para os micênios no continente, a origem cretense do conteúdo. Por fim, Driessen, Farnoux e Langohr (2015) afirmam que as inscrições foram realizadas como elementos visuais, e, contrário às teses de van Alfen e Duhoux, não teriam uma função de leitura, estando associados ao recipiente e não ao seu conteúdo. Os vasos com inscrições seriam, desta forma, presentes que mencionariam o doador, uma prática atestada em Homero, mas também nos períodos Clássico e Helenístico.

Com relação a esta última hipótese, como com relação à abordagem de Duhoux, gostaria de fazer uma objeção que diz respeito à utilização de documentos de épocas posteriores ou de outras sociedades para inferir comportamentos sociais no mundo micênico. Em ambos os casos é preciso proceder com cautela e não transpor automaticamente práticas de uma época para, outra ou de uma sociedade para outra. Tanto as abordagens de van Alfen, Duhoux e Driessen, Farnoux e Langohr parecem considerar Creta e o continente como duas áreas administrativas e econômicas distintas, e a elite cretense como sendo não micênica.

\section{O estudo dos vasos de Tebas}

Tebas é um sítio situado na Beócia com uma história de ocupação desde o Neolítico. Um dos problemas da pesquisa de Tebas é que a cidade moderna está assentada sobre a antiga, e as escavações só acontecem pontualmente quando alguma obra é realizada no perímetro urbano. No entanto, o sítio tem fornecido importantes vestígios do período micênico. No sítio, 74 vasos e fragmentos com inscrições do Cadmeion (Catling et al., 1980) e 27 tabletes foram encontrados em um edifício próximo denominado Arsenal.

Heródoto, Unifesp, Guarulhos, v.5, n.1 - 2020.1. p. $43-59$

DOI: $10.34024 /$ herodoto.2020.v5.11780 
A 150 metros a oeste do Arsenal mais 17 tabletes foram escavados na sala dos Arquivos. A 70 metros a sudeste do Arsenal, próximo ao portão Homoloïdes (Homoloides Gate) havia um depósito de 56 nódulos inscritos em Linear B (Piteros; Olivier; Melena, 1990, p. 105). Todos esses documentos foram datados, a partir da cerâmica, entre 1300 e 1200 a.C. Recentemente, 250 tabletes e fragmentos foram escavados na Rua Pelopidou na área do Arsenal e datados de 1350/1300 a.C., e alguns selos e um tablete foram encontrados na área do Tesouro e datados do 1300/1200 a.C.

O sítio de Tebas na possui o maior conjunto de vasos com inscrição, dos quais 62 vieram do corredor Delta, um contexto bem definido de armazenamento no edifício principal, denominado Cadmeion, onde foram encontrados juntamente com outros 120 vasos com alça em estribo sem inscrição. Dentre os vasos inteiros ou reconstituídos, 15 possuem inscrição com três palavras (antropônimo + topônimo + antropônimo), 23 apenas uma palavra (antropônimo), 3 cuja palavra não pode ser identificada e 4 que portam o sinal identificado como ka. O conjunto ainda é composto por 29 fragmentos de vaso com alça em estribo.

No grupo de inscrições de três palavras, 14 vasos trazem o topônimo wato, localidade do oeste de Creta. A décima quinta é uma inscrição cuja terceira palavra é wa-na-ka-te-ro, entendido pelos estudiosos como significando "do wanax", e o topônimo o-do-ru-wi-jo, também do oeste de Creta. Tal fato é corroborado pelas análises realizadas na argila de 54 dos vasos de Tebas, dentre os quais 46 tiveram a origem da argila atribuída ao oeste de Creta e apenas 8 de produção local. Todos os vasos com três palavras foram produzidos em Creta.

Desta maneira, é preciso considerar que o conjunto de vasos de Tebas representa um contexto primário, tendo em vista que o contexto de achado é significativo, uma vez que os vasos estavam armazenados no principal edifício do sítio. Sendo assim, embora tenham sido fabricados em Creta a produção foi direcionada para Tebas, conclui-se que, através da análise dos documentos em Linear B, com relativa segurança que este centro controla a produção de óleo do oeste de Creta, sem que isso tenha se traduzido em uma ocupação militar ou populacional da parte ocidental da ilha por parte dos micênios.

Heródoto, Unifesp, Guarulhos, v.5, n.1 - 2020.1. p. 43-59

DOI: $10.34024 /$ herodoto.2020.v5.11780 


\section{Conclusão}

A administração micênica possui várias categorias de documentos e voltava-se, sobretudo, para o controle de algumas atividades econômicas específicas. Na esfera local temos os selos, utilizados principalmente para o controle dos armazéns dos centros. Em um segundo nível, o regional, temos os tabletes que, embora tenham sido produzidos nos escritórios dos edifícios centrais, registravam informações coletadas em outras localidades, e os nódulos, que viajavam juntamente com os bens que eram entregues nos centros. Por fim, haviam os vasos, produzidos para transportar o óleo produzido em Creta para o continente.

Ao que tudo indica os vasos com inscrição parecem apontar para a existência de funcionários ou elites continentais micênicos atuando direta ou indiretamente em Creta, controlando uma produção de óleo que tinha como meta o envio de produtos para o continente. Tebas seria, nesse caso, o centro que comandava a produção estabelecida no oeste de Creta, que tinha em Cidônia um centro de segunda ordem submetido ao centro continental. Desta maneira, a organização econômica micênica, que parece ter sido organizada para participar do comércio de luxo estabelecido no Mediterrâneo oriental, teria se aproveitado de uma organização minoica pré-existente e estruturado um controle administrativo que prescindia de uma ocupação efetiva e massiva de áreas produtivas em outras localidades.

\section{Referências Bibliográficas}

BENNET, J. "Collectors" or "Owners"? An Examination of their Possible Functions within the Palatial Economy of LM III Crete. In: OLIVIER, J.-P. (Ed.) Mykenaika. Actes du IXe Colloque international sur les textes mycéniens et égéens organisé par le Centre de l'Antiquité Grecque et Romaine de la Fondation Hellénique des Recherches Scientifiques et l'École française d'Athènes. Bulletin de Correspondance Hellénique, suppl. XXV, 1992, p. 65-101.

BENNET, J. Agency and Bureaucracy: Thoughts on the Nature and Extent of Administration in Bronze Age Pylos. In: VOUTSAKI, S.; KILLEN, J. (Eds.) Economy and Politics in the Mycenaean Palatial States. Cambridge: Cambridge Philological Society, 2001, p. 25-37. 
CARLIER, P. Les collecteurs sont-ils des fermiers? In: OLIVIER, J.-P. (Ed.) Mykenaïka. Actes du IXe Colloque international sur les textes mycéniens et égéens organisé par le Centre de l'Antiquité Grecque et Romaine de la Fondation Hellénique des Recherches Scientifiques et l'École française d'Athènes. Bulletin de Correspondance Hellénique, suppl. XXV, 1992, p. 159166.

CATLING, H. W. et al. The Linear B Inscribed Stirrup Jars and West Crete. Annual of the British School at Athens 75, 1980, p. 49-113.

CHADWICK, J. Linear B and related scripts: Reading the Past. London: British Museum Publications, 1987.

DRIESSEN, J. “Collector's Items". Observations sur l'élite mycénienne de Cnossos. In: OLIVIER, J.-P. (Ed.) Mykenaïka. Actes du IXe Colloque international sur les textes mycéniens et égéens organisé par le Centre de l'Antiquité Grecque et Romaine de la Fondation Hellénique des Recherches Scientifiques et l'École française d'Athènes. Bulletin de Correspondance Hellénique, suppl. XXV, 1992, p. 197-214.

DRIESSEN, J. Le Palais de Cnossos au MR Il-Ill: Combien de destructions? In: DRIESSEN, J. ; FARNOUX, A. (Eds.) La Crète Mycénienne. Actes de la Table Ronde internationale organisée par l'École Française d'Athèns, 2328 mars 1991. Bulletin de Correspondance Hellénique, suppl. 38, 1997, p. 113134.

DRIESSEN, J.; FARNOUX, A.; LANGOHR, C. Two more Linear B Inscribed Stirrup jars from Malia. In: KAISER, I; KOUKA, O.; PANAGIOTOPOULOS, D. (Eds.) Ein Minoer im Exil: Festschrift zum 65 Geburtstag von Wolf-Drietrich Niemeier, Bonn, 2015, p. 25-40.

DUHOUX, Y. La fonction des vases à étrier inscrits en Linéaire B. Kadmos 49, 2011, p. 47-92.

EVANS, A, J. The Palace of Knossos: Provisional Report for the Year 1903. Annual of the British School at Athens 8, 1902-3, p. 1-153.

FURUMARK, A. The Mycenaean Pottery. Stockholm: Victor Petterson, 1941.

GODART, L. Les collecteurs dans le monde égéen. In: OLIVIER, J.-P. (Ed.) Mykenaïka. Actes du IXe Colloque international sur les textes mycéniens et égéens organisé par le Centre de l'Antiquité Grecque et Romaine de la Fondation Hellénique des Recherches Scientifiques et l'École française 
d'Athènes. Bulletin de Correspondance Hellénique, suppl. XXV, 1992, p. 257283.

HASKELL, H. W. The Origin of the Aegean Stirrup Jar and Its Earliest Evolution and Distribution. (MB III - LBI). American Journal of Archaeology 89, 1985, pp. 221-229.

JUDSON, A. P. The Linear B Inscribed Stirrup Jars. Kadmos 52, 2013, p. $69-$ 110.

KILLEN, J. T. Some Further Thoughts on "Collectors". In: LAFFINEUR, R.; NIEMEIER, W.-D. (Ed.) Politeia. Society and state in the Aegean Bronze Age. Proceedings of the 5th International Aegean Conference / 5e Rencontre égéenne internationale, University of Heidelberg, Archäologisches Institut, 10-13 April 1994, Aegaeum 12, 1995, p. 213-226.

KILLEN, J. T, Some Thoughts on ta-ra-si-ja. In: VOUTSAKI, S.; KILLEN, J. T. (Eds.) Economy and Politics in the Mycenaean Palace States. Proceedings of a Conference held on 1-3 July 1999 in the Faculty of Classics. Cambridge: Cambridge Philological Society, 2011, p. 161-180.

LIVERANI, M. Antigo Oriente: História, Sociedade e Economia. São Paulo: Edusp, 2016.

MARAN, J. Late Minoan Coarse Ware Stirrup Jars on the Greek Mainland. A Postpalatial Perspective from the 12th Century BC Argolid. In: D'AGATA, A. L.; MOODY, J. (Eds.) Ariadne's Threads: Connections between Crete and the Greek Mainland in Late Minoan III (LM IIIA2 to LM IIIC). Proceedings of the International Workshop Held at Athens, 2003. Scuola Archeologica Italiana: Athens, 2005, p. 415-431.

PALAIMA, T. G. 'Archives' and 'Scribes' and Information Hierarchy in Mycenaean Greek Linear B Records. In: BROSSIUS, M. (Ed.) Ancient Archives and Archival Traditions. Oxford: Oxford University Press, 2003, p. 153-194.

PITEROS, C. ; OLIVIER, J.-P. ; MELENA, J. L. Les Inscriptions en linéaire $B$ des nodules de Thèbes (1982): La fouille, les documents, les possibilités d'interprétation, Bulletin de Correspondance Hellénique 114, 1990, p. 103-181.

PLUTA, K. Aegean Bronze Age Literacy and Its Consequences. PhD thesis. University of Texas, 2011. 
SHELMERDINE, C. W. The Perfume Industry of Mycenaean Pylos. Göteborg: Paul Astroms Forlag, 1985.

SHELMERDINE, C. W. (Ed.) The Cambridge Companion to the Aegean Bronze Age. Cambridge: Cambridge University Press, 2008.

VAN ALFEN, P. G. The Linear B Inscribed Stirrup Jars as Links in an Administrative Chain. Minos 31, 1997, p. 251-274.

VENTRIS, M.; CHADWICK, J. Documents in Mycenaean Greek: Three Hundred Selected Tablets from Knossos, Pylos and Mycenae with Commentary and Vocabulary. Cambridge: Cambridge University Press, 1953.

ZURBACH, J. Les vases inscrits en linéaire B: tentative d'interpretation globale. Mitteilungen des Deutschen Archäologischen Instituts. Athenische Abteilung 121, 2006, p. 13-71. 